\title{
«Yo, Olga Orozco» La multiplicidad, la unidad primordial y el eterno retorno en la composición poética de Olga Orozco (1920-1999).
}

KatHerina Mansilla Fuentes

Universidad Autónoma de Madrid

Resumen: La composición poética de Olga Orozco se caracteriza por la homogeneidad de su estilo, así como de su correlato filosófico. Se considera que, para ello, la arquitectura discursiva de la obra orozquiana se configura de manera análoga a su contenido. En este, la visión metafísica del mundo que tiene Orozco se sostiene sobre la idea de unidad primordial, un estado anterior de la materia, cuya pérdida fundamenta la búsqueda perpetua de la autora. Por consiguiente, en el presente trabajo se analizará la interrelación entre la multiplicidad como rasgo temático y condición del sujeto poético y la repetición como recurso representativo, que, a su vez, refuerza el tema del eterno retorno o de la no direccionalidad del tiempo.

Palabras clave: Olga Orozco, poesía, centenario, multiplicidad, unidad primordial, eterno retorno.

«Yo, Olga Orozco». Multiplicity, the Primordial Unit, and the Eternal Return in Olga Orozco's Poetic Composition

Abstract: Olga Orozco's poetic composition is characterized by the homogeneity in her style and in its philosophical correlate. To achieve this trait, the discourse architecture in Orozco's oeuvre is believed to be constructed analogously to the content therein. Regarding the latter, Orozco's metaphysical worldview is sustained by the notion of the primordial unit, a prior state of matter, the loss of which underlies the author's perpetual quest. Accordingly, this paper analyses the interrelationship between multiplicity as a thematic feature and as a condition of the poetic subject and repetition as a representative resource, which, in turn, reinforces the topic of the eternal return and the non-directionality of time.

Palabras clave: Olga Orozco, Poetry, Centennial, Multiplicity, Primordial Unit, Eternal Return. 


\section{Introducción}

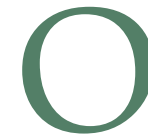

lga Orozco, a través de su premiada obra, se ha convertido en una de las voces esenciales de la poesía hispanoamericana del siglo xx. En el año del centenario de su nacimiento, resulta preciso recordar sus orígenes, allí donde vida y poesía se unen indefectiblemente. Los médanos característicos de su Toay natal (La Pampa, Argentina), que componen, para la autora, un paisaje infinito y mutante, se convierten, en su universo poético, en un espacio al que volver, propulsor de la nostalgia y de sus primeras conjeturas acerca de la autenticidad de la realidad: «Sé que de todos modos la realidad es errante / tan sospechosa y tan ambigua como mi propia anatomía» (Orozco, 2013: 223) ${ }^{1}$. Asimismo, sus abuelas la conectan con la tradición irlandesa - genealogía materna - , en la cual se atribuye poderes mágicos a los objetos, y la cultura siciliana - genealogía paterna - , de temperamento apasionado y excesivo (Sefamí, 1996), influencia que se estima germen fundacional de sus vertientes metafísicas y del carácter de sus letras, respectivamente. Con tan solo 15 años, y luego de vivir en Bahía Blanca, llega a la Ciudad de Buenos Aires, donde comienza a reunirse en tertulias nocturnas con los literatos de su época - luego recordados, con matices de aceptación, como Generación del 40 - (Moscona, 1999) y a realizar sus primeras publicaciones (Zonana, 2010). Por otra parte, cabe mencionar que Olga Nilda Gugliotta toma el apellido de su madre, Cecilia Orozco, para firmar sus poemas, hecho que acentúa la importancia de las figuras femeninas de su familia en su obra.

En el presente artículo se estudia la interrelación entre la multiplicidad inherente al sujeto poético: «Yo, Olga Orozco, desde tu corazón digo a todos que muero» (Orozco, 2013: 101), así como a los planos de aquello que llamamos realidad o mundo sensible y la función del recurso de repetición como estructura discursiva análoga al contenido temático y filosófico de la obra orozquiana. En este, se fundamenta la búsqueda perpetua que asume el yo poético a través del tema de la pérdida de la unidad primordial - en términos de la autora - . Cabe señalar que, el concepto de unidad primordial, que Orozco describe como un estado anterior de la materia, se desprende de la figura del ángel caído, según los textos bíblicas: «¡Como caíste del cielo, oh Lucifer, hijo de la mañana! Derribado fuiste a tierra, tú que debilitabas a las

1 En este trabajo, a fines prácticos, se citará la obra de la autora desde Poesía Completa (2013), por lo que el año de publicación siempre se corresponderá con el de este volumen póstumo. 
naciones» («versión en español estándar», Is. 14. 12). Esta visión del mundo es abordada, a su vez, a través de múltiples puntos de vista: el ocultismo, el gnosticismo, el vedismo ${ }^{2}$, el misticismo. En este sentido, resulta de interés observar que la indagación metafísica desestabiliza, en consecuencia, las cualidades del concepto de tiempo. Por tanto, se considera que el modo en que se corresponden los aspectos antes mencionados es determinante en la constitución y desarrollo de una voz caracterizada por su solidez y homogeneidad, en la que se reconoce un «afán totalizador, una pretensión de síntesis en la que se disuelven los contrarios» (Colombo, 1983: 28). Por su parte, el eclecticismo de las bases ideológicas de esta obra es consonante con su estilo entre neorromántico ${ }^{3}$ y surrealista ${ }^{4}$ que no responde de forma pragmática a sus doctrinas, es decir, que Olga Orozco trata de manera libre, en función de sus propias necesidades literarias.

La autora describe en sus poemarios una búsqueda hacia arriba, en referencia a la elevación del alma, mediante la religión y el misticismo y otra hacia abajo, en remisión al llamado de fuerzas oscuras (Sefamí, 1996). A nivel gráfico, estas declaraciones ayudan a pensar que su producción no evoluciona en un sentido lineal, sino que crece a partir de ejes determinados, ya que vuelve y profundiza sobre los mismos: la mencionada búsqueda hacia arriba y hacia abajo y la multiplicidad - que podría considerarse una proliferación

2 En los textos del Rig Veda - de los cuales, Orozco extrae el epígrafe del poemario Los juegos peligrosos (1962): «Lo eterno es uno, pero tiene muchos nombres» (Rig Veda) - se observa un evidente paralelismo de algunos de los conceptos que rigen la obra orozquiana. A saber: los cuatro Vedas (Rig Veda, Sama Veda, Yajur Veda y A tharva Veda) constituyen «el texto más antiguo de la cultura de la India, escrito en sánscrito, y que si bien no es de naturaleza filosófica contiene con todo los primeros intentos de reflexión filosófica [...] De los cuatro Vedas el más antiguo es el Rig Veda que debemos ubicar hacia el inicio de la Época Védica, alrededor del año 1500 antes de Cristo.[...] Dos ideas de los Vedas son especialmente interesantes para el propósito de este trabajo: la idea de que el origen de todo fue lo Uno (ekam) y la idea de un Orden Cósmico que todo lo regula (rita). La primera tiene que ver con la creación y la segunda con el funcionamiento del mundo» (Tola, Dragonetti, 2003:217-218).

3 Anibal Salazar (2010) realiza un estudio detallado acerca de la relación entre «Olga Orozco y la generación neorromántica del 40. Una revisión crítica», en Inmaculada Lergo (coord.), Territorios de fuego para una poética.

4 En palabras de Blanco: «Más allá de sus relaciones con las corrientes literarias de su época, 'Generación del $40^{\prime}$, neorromanticismo y surrealismo, la obra orozquiana se desarrolla fuertemente determinada por su trayectoria vital, por su especial relación con el mundo, impregnada de presagios, esoterismo y conjuros, con un temor declarado a la muerte» (2009: 14). En general, los estudiosos de Olga Orozco coinciden con la anterior afirmación. Además, en la «Cronología» de su Poesía completa, se especifica que, en 1936, la autora «lee a los poetas que luego reconocerá como influencias: Rilke, Milosz, los poetas románticos, los poetas españoles de la Generación del 27, especialmente Cernuda» (Orozco, 2013: 482), a quien dedica el poema «La realidad y el deseo», en Mutaciones de la realidad (1979). 
horizontal del sujeto poético y sus mundos-. Esta reflexión sobre el desarrollo de la producción orozquiana se complementa con la circularidad de su compulsión al retorno, que, con mayor énfasis hacia el final de su obra, está ligada al temor a la muerte. En relación con ello, los versos finales de su último poemario publicado en vida rezan: «Madre, madre, / vuelve a erigir la casa y bordemos la historia. / Vuelve a contar mi vida» (Orozco, 2013: 429). Por otra parte, dicha circularidad se refleja, en lo formal, de manera extrínseca, mediante poemas en los que se condensa su universo, los cuales aparecen principalmente en la apertura y cierre de sus libros y, de forma intrínseca, a través de la repetición.

\section{La multiplicidad y el sujeto poético en la obra orozquiana}

El desdoblamiento del yo poético de Olga Orozco se encuentra condicionado por el contexto metafísico y múltiple propio de su mundo temático. La autora «traza una trayectoria singularmente rica y productiva en cuanto al descentramiento extremo y ulterior rearticulación» (Piña, 2010: 148) de este, de tal modo que adquiere la cualidad de transgredir las limitaciones que tiene su ente físico para comunicarse, el cual, Orozco, se dedica a explorar en su cuarto poemario, Museo salvaje (1974): «pero estas que prolongan mi espesa anatomía [...] no son manos que sirvan para entreabrir las sombras» (Orozco, 2013: 171); «[...] hasta la ciega condena de estos ojos que me impiden mirar» (Orozco, 2013: 176); «No me sirve esta piel que apenas me contiene, esta cáscara errante que me controla y me recuenta, / esta túnica avara cortada en lo invisible a la medida de mi muerte visible» (Orozco, 2013: 179).

En consecuencia, el desdoblamiento del yo poético, así como los distintos planos de la realidad convergen en la idea de unidad primordial y de un yo-todos. La no dualidad o «conjugación de factores de signo diverso, que recuerda la pretensión superrealista de superación de antinomias» (Colombo, 1983: 28) puede observarse en su obra a través de la coexistencia no excluyente de los siguientes conceptos $^{5}$ : vida y muerte; visible e invisible; tangible e inasible; religión y ocultismo; cuerpo y alma; abismo y paraíso; memoria y olvido; envoltura e intemperie; sueño y vigilia. En este sentido, Tamara Ka-

5 Algunos de los ejemplos mencionados también son indicados por Diana Irene Blanco (2009). 
menszain (2013) hace referencia a la díada yo-tú ${ }^{6}$. Al respecto, puede decirse que el enajenamiento ontológico que el sujeto siente con relación a su propio cuerpo es efecto de la nostalgia, tras la caída al mundo físico, por su estado anterior. «Estoy hecho con la misma sustancia del abismo / y oficio contra la nada mi caída en las inmóviles tinieblas» (Orozco, 2013: 262). Por lo que, de acuerdo con sus influencias bíblicas - fundamentales en su obra - , el alma asume en reiteradas ocasiones el desdoblamiento del sujeto poético - yo-alma-, que, además, «envuelto en el movimiento de la repetición, deviene plural» (Kamenszain, 2013: 8). En este sentido, Olga Orozco se manifiesta con las siguientes palabras:

¿Cómo hago para hablar de mi yo, si mi yo es una cosa circunstancial, es un yo que me corresponde en este momento, y en este aquí absolutamente enajenado de todo lo que me rodea que no es yo? [...] la pregunta es ¿quiénes somos todos? Cuando yo pongo mi yo quiero poner todos (Sefamí, 1996: 105).

La interrelación del yo poético orozquiano con un universo que se caracteriza por la unidad transustancial de sus elementos, lo acerca al concepto de intersubjetividad ${ }^{7}$, por lo que es susceptible de ser calificado como sujeto poético metafísico. Cristina Piña (2010), en Territorios de fuego para una poética, resume las diversas formas del sujeto poético a lo largo de la historia. A saber: Fitche propone la existencia de un yo absoluto, Schelling la vinculación entre la naturaleza y el espíritu, Béguin una voz-otra que es el alma del mundo y Nietzsche

\footnotetext{
6 La díada tú-yo «trabaja con fuerza en toda la primera parte de la obra orozquiana. Incluso en el emblemático poema titulado 'Olga Orozco', donde se lanza a rodar una firma que, en el primer verso, vuelve a confirmar por duplicado la actualidad del nombre como afirmación de la muerte propia -'Yo, Olga Orozco, desde tu corazón digo a todos que muero' - y el yo queda desdoblado en la esfera de un tú. Mientras veinte años antes 'César Vallejo ha muerto' denunciaba la no coincidencia entre la identidad del autor y la universalidad de un nombre puesto a jugar tapas adentro de un libro (Kamenszain, 2013: 8).

7 Intersubjetividad: «...cuyos sujetos singulares están provistos de sistemas constitutivos que se corresponden y conexionan los unos con los otros. [...] Lo primero ajeno en sí (lo primero 'no-yo') es, pues, el otro yo. $Y$ ello posibilita constitutivamente un dominio nuevo e infinito de objetos ajenos, una naturaleza objetiva y, en general, un mundo objetivo, al que pertenecemos los otros todos y yo mismo. Es cosa que se halla en la esencia de esta constitución que se eleva a partir de los otros 'puros' (que carecen aún de sentido mundanal) el que los 'otros' respecto de mí no queden aislados; que, más bien, se constituya (naturalmente, en la esfera de lo mío propio) una comunidad de yoes - que me incluye a mí mismo - como comunidad de yoes que existen unos con otros y unos para otros; en último término, una comunidad de mónadas, y una tal que constituye (en su intencionalidad mancomunada constituyente) el mundo único e idéntico. En este mundo se presentan luego de nuevo todos los yoes, pero en tanto que objetos del mundo, en apercepción objetivadora, con el sentido de 'hombres' o de hombres psicofísicos» (Husserl, 1996: 169-170).
} 
un yo transpersonal, atravesado por las fuerzas cósmicas de lo universal. Cabe destacar - sin dejar de valorar la muerte ${ }^{8}$ como uno de los principales ejes temáticos de su poesía - que, según palabras de la propia autora, los planos que indaga cuando escribe «no tienen que ver con la muerte sino con el plano de lo que no es de este mundo, sino que está más allá, otra vida. Una zona paralela donde duermen los motivos por los que estamos acá» (Dillon, 1999: s.p.).

1. como si no supiéramos que el cuerpo no es de aquí, que viene de muy lejos y se va, sin aclararnos nunca si es reverso del alma, una opaca versión de lo invisible, una trampa superflua, ¿o un nudo, sólo un espeso nudo en la gran transparencia? ¿Y a qué modelo alude con su muerte final ese intérprete ciego, el mártir, el incauto, el que no sabe, el que apaga las luces y cierra el escenario de este lado?

«El narrador» (Orozco, 2013: 361).

2. Desde adentro de todos no hay más que una morada bajo un friso de máscaras;

desde adentro de todos hay una sola efigie que fue inscripta en el revés del alma

desde adentro de todos cada historia sucede en todas partes:

no hay muerte que no mate,

no hay nacimiento ajeno ni amor deshabitado.

«Desdoblamiento en máscara de todos» (Orozco, 2013: 156).

A propósito de la idea de recuperar la unidad primordial - unidad de todo-, Orozco especula que antes «habitábamos un lugar que no era, como el mundo, un efímero relámpago de lo invisible en la materia, y si era tal, no establecía límites, de modo que cada uno éramos como una parte de un solo organismo que tenía un yo central: el de Dios» (Dillon, 1999: s.p.). De esta

8 Además de abordar la muerte como tema per se, Olga Orozco escribe elegías eventuales, dedicadas a familiares y seres queridos, y reúne dos poemarios completos con motivo de la muerte: Las muertes (1952) y Cantos a Berenice (1977), el cual consiste en un solo poema dividido en 17 cantos, escrito para su gata, su emisaria, tras su muerte. 
manera, fundamenta su inquietud por explorar lo inasible, en el ejercicio poético, con marcados matices religiosos. El tratamiento orozquiano de lo metafísico proviene, en distintas medidas, de las estéticas romántica alemana y surrealista ${ }^{9}$, que, sin duda, se actualizan al tomar contacto con las particularidades propias de Orozco.

\section{La repetición como figura estructural del eterno retorno o de la no direccionalidad del tiempo}

La estructura formal que sostiene las singularidades señaladas hasta el momento en la poesía de Olga Orozco, replica en sí misma el desdoblamiento de la realidad y el descentramiento del sujeto poético. La forma, como objeto de estudio, permite reflexionar sobre la organización de los recursos literarios y el efecto que esta tiene sobre el contenido de las obras en distintos niveles, es decir, en unidades de distinta jerarquía y tamaño: poemario, poema, estrofas, versos, títulos, etc. El manejo de la lengua como materia prima compositiva determina la arquitectura que sostiene a estas producciones artísticas, que, en el caso de Olga Orozco, fortalece y expande las funciones semánticas, semióticas y gramaticales. En una obra cuya unidad estilística ha sido señalada por diversos investigadores, la abstracción, como ejercicio de creación, posibilita la flexibilización de distintos conceptos, como ocurre, en particular, con el del tiempo. Este fenómeno que se revela a través del retorno a su infancia y de la búsqueda de un estado anterior del mundo sensible, se elabora mediante reiteradas referencias temporales, sobre todo, con relación a lo eterno o aquello que perdura: «Basta que una palabra me atraviese de pronto lado a lado, / Sobre todo si es siempre, sobre todo si es nunca, o acaso, o demasiado» (Orozco, 2013: 299); «Guardadla para siempre en esta misma puerta abierta en el celaje de los siglos, / donde se balancea despidiéndose» (Orozco, 2013: 82). También, se expresa en imágenes que desdibujan la frontera entre el tiempo y el espacio; incorporando, además, el recurso de la personificación, como ocurre en el poema «Variaciones sobre el tiempo»: «Nunca se acompasaron nuestros pasos en estos entrecruzados laberintos / Ni siquiera al comienzo» (Orozco, 2013: 266); «Hemos luchado a veces cuerpo a cuerpo. / Nos hemos disputado como fieras cada porción de amor, / cada pacto firmado con la tinta que fragua en alguna instantánea eternidad» (Orozco, 2013: 267). Por último, en lo formal, como ya se ha mencionado, a través de las técnicas de repetición - aliteraciones, anáfo- 
ras - . A continuación, se presentan algunos ejemplos:

a. En este primer caso, que pertenece al poema de apertura de su primer libro, repite frases o palabras en el interior o en el exterior de cada sección, generando un efecto envolvente y circular que construye la imagen subyacente del retorno.

A veces sólo era un llamado de arena en las ventanas, Una hierba que de pronto temblaba en la pradera quieta, Un cuerpo transparente que cruzaba los muros con blandura Dejándome en los ojos un resplandor pesado, O el ruido de una piedra recorriendo la indecible tiniebla de la medianoche; a veces, sólo el viento.

Reconocía en ellos distantes mensajeros de un país abismado con el mundo bajo las altas sombras de mi frente. Yo los había amado, quizás, bajo otro cielo, Pero la soledad, las ruinas y el silencio eran siempre los mismos.<smiles></smiles>

Tú no respondes nada, porque toda respuesta de ti ha sido dada.

Acaso hayas vivido solamente Aquello que al arder no deja más que polvo de tristeza inmortal, Lo que saluda en ti, a través del recuerdo, Una eterna morada que al recibirnos se despide.

Tú no preguntas nada, nunca, porque no hay nadie ya que te responda. «Lejos, desde mi colina» (Orozco, 2013: 23-24).

b. Otro uso de la repetición, en el mismo sentido que en el ejemplo anterior, se observa aquí, aplicado al poema completo, es decir, en su primer y último verso:

Esta mansión de Ulsgaard se colmó con la muerte de Christoph Detlev Brigge. 
En esta mansión vaga solamente la muerte de Christoph Detlev Brigge envuelta en estandartes imperiales.

c. Por otra parte, la anáfora refuerza la multiplicidad del yo poético, así como del espacio y del tiempo:

Están aquí, reunidas alrededor del viento,

La niña clara y cruel de la alegría, coronada de flores polvorientas;

La niña de los sueños, con su tierno cansancio de otro cielo recién abandonado;

La niña de la soledad, buscando entre la lluvia de las alamedas el secreto del tiempo y del relámpago;

La niña de la pena, pálida y silenciosa,

Contemplando sus manos que la muerte de un árbol oscurece;

La niña del olvido que llama, llama sin reposo sobre su corazón adormecido,

Junto a la niña eterna,

La piadosa y sombría niña de los recuerdos que contempla borrarse una vez más.

«Quienes rondan la niebla» (Orozco, 2013: 26-27).

d. En el siguiente fragmento del poema «Repetición del sueño» - siendo este, otro plano al que Olga Orozco suele aludir - aparecen imágenes circulares, seguidas del uso de la anáfora que, a su vez, contiene un sujeto poético desdoblado, por lo que se produce una atmósfera que acentúa el descentramiento del sentido de unicidad de la realidad:

girando con un lento remolino de adiós, así voy convocada, sin remedio, hasta alcanzar mi sombra de extranjera en la niebla, hasta pasar los muros que llevan paso a paso a la condena, hasta entrar en la noche en que el malhechor asume las apariencias del sueño 
«Repetición del sueño» (Orozco, 2013: 118).

e. En su último poemario publicado en vida, se encuentra un uso más elaborado de este recurso, en el que concentra la repetición en el interior de los versos:

Nuestro largo combate fue también un combate a muerte con la muerte, poesía.

Hemos ganado. Hemos perdido, porque ¿cómo nombrar con esta boca, cómo nombrar en este mundo con esta sola boca en este mundo con esta sola boca?

«Con esta boca, en este mundo» (Orozco, 2013: 390).

Otra interrelación predominante en la producción orozquiana es la que ocurre con las puertas - «Innumerables puertas: / os contemplo otra vez desde las grietas piadosas de los tiempos» (Orozco, 2013: 36) - que, como objeto y símbolo de comunicación entre espacios, refuerzan el concepto de multiplicidad de estados a través de los suyos propios, es decir, aparecen de modo recurrente: abiertas, cerradas o entreabiertas. Es preciso indicar que, como opuesto de estas aparecen los muros y las paredes. En el siguiente ejemplo se observa el recurso de la repetición, y su señalado efecto de circularidad, que intensifica el desánimo ante la imposibilidad de acceso - de pasar hacia el otro lado - que representa un muro: «Paso a paso a lo largo de la pared que fue visión tramposa, / transparencia entreabierta, / y ahora está cerrada como boca cerrada / - como estarán cerrados los oídos de mis sobrevivientes al reclamo obstinado-» (Orozco, 2013: 345). A su vez, la reiteración responde a la relación que existe entre los conjuros y los números mágicos y, como técnica formal, a los rezos y los rituales, frecuentes en la poesía de Olga Orozco. A continuación, se cita, a modo ejemplo, el principio del poema «Para ser otra», de Los juegos peligrosos (1962), poemario dedicado a explorar su búsqueda «hacia abajo»:

Una palabra oscura puede quedar zumbando dentro del corazón.

Una palabra oscura puede ser el misterio de otros nombres que tuve.

Una palabra oscura puede volver a levantar el fuego y la ceniza.

“Matrika Doléesa, 
llora por mí.

Matrika Doléesa, vuelve por mí.

Ven a buscar el ascua del esplendor sepultada en mi mano"

«Para ser otra» (Orozco, 2013: 120)

\section{Conclusión}

Olga Orozco, a través de una elaborada ingeniería literaria, trasciende las fronteras del cuerpo, el mundo tangible y el tiempo. A cien años de su nacimiento, resulta preciso promover la difusión y el estudio de la obra de esta autora que fue inquebrantablemente fiel a su unicidad. Voz indiscutible de la poesía hispánica, única mujer recordada de la Generación del 40: Olga Orozco.

\section{Referencias bibliográficas}

Orozco, Olga (2013), Poesía completa, Buenos Aires, Adriana Hidalgo Editora S. A.

Blanco, Diana Irene (2009), Olga Orozco: la jerarquía de la palabra, Buenos Aires, Dunken.

Colombo, Stella Maris (1983), Metáfora y cosmovisión en la poesía de Olga Orozco, Argentina, Cuadernos Aletheia de Investigación y Ensayo.

FERNÁNDEZ MoReno (1967), César, La realidad y los papeles, panorama y muestra de la poesía argentina, Madrid, Aguilar.

Husserl, Edmund (1996), Meditaciones cartesianas, (trad. Gaos, J. y García-Baró, M.), México D. F., Fondo de Cultura Económica. En línea: <https:/ / richardfong.files.wordpress.com/2011/02/ husserl-edmundmeditaciones-cartesianas-fce-1996.pdf>. Último acceso: 30-jun-2020.

Santa Biblia, Antiguo y nuevo testamento (2009), Utah, EE. UU., La iglesia de Jesucristo de los Santos de los Últimos Días. En línea <https://media. 
ldscdn.org/pdf/lds-scriptures/holy-bible/holy-bible-spa.pdf>. Último acceso: 30-jun-2020.

SAUTER, Silvia (2006), Teoría y práctica del proceso creativo: con entrevistas a Ernesto Sábato, Ana María Fagundo, Olga Orozco, María Rosa Lojo, Raúl Zurita y José Watanabe, Madrid, Iberoamericana.

Sefamí, Jacobo (1996), De la imaginación poética: conversaciones con Gonzalo Rojas, Olga Orozco, Alvaro Mutis y José Kozer, Caracas, Monte Ávila Editores.

Zonana, Gustavo y Castellino, Marta (2008), Poesía argentina, dos miradas, Buenos Aires, Corregidor.

CAmpos, Marco Antonio (1999), «Entrevista con Olga Orozco, Nada hay más indefenso que la dicha», en La Jornada Semanal, 31 de enero. En línea: <https:/ / www.jornada.com.mx/1999/01/31/sem-orozco.html>. Último acceso: 30-jun-2020.

Dillon, Marta (1999). «Olga Orozco X Marta Dillon, La Orozco (Glorias)», en Página, 12. 28 de mayo. En línea: <https://www.pagina12.com.ar/ diario/verano12/23-79414-2007-01-23.html>. Último acceso: 30-jun-2020.

Kamenszain, Tamara (2013), «Prólogo», en Olga Orozco, Poesía completa, Buenos Aires, Adriana Hidalgo Editora, págs. 7-18.

LERGO, Inmaculada (2010a), «Presentación», en Inmaculada Lergo (coord.), Territorios de fuego para una poética, Sevilla, Universidad de Sevilla.

(2010b), «Decir lo indecible. Olga Orozco o la revelación a través de la palabra», en Inmaculada Lergo (coord.), Territorios de fuego para una poética, Sevilla, Universidad de Sevilla.

(2011), «Un rehén en las tinieblas: visión del cuerpo en Museo Salvaje de Olga Orozco», en Ramírez Almazán, Dolores (ed.). In corpore dominae. Cuerpos escritos/Cuerpos proscritos. Sevilla, ARCiBEL, págs. 113-145.

Millares, Selena (2010), «Olga Orozco, peregrina de la muerte», en Inmaculada Lergo (coord.), Territorios de fuego para una poética, Sevilla, Universidad de Sevilla.

Moscona, Myriam (1999), «Entrevista con Olga Orozco, La puerta que no 
abriste», en La Jornada Semanal, 29 de agosto. En línea: <https://www. jornada.com.mx/1999/08/29/sem-myriam.html>. Último acceso: 30jun-2020.

NAVARro, Marianela (2000), «El oculto territorio de Olga Orozco», en Cuadernos Hispanoamericanos, 597, págs. 129-131.

PIÑA, Cristina (2010), «El descentramiento del sujeto en la poesía de Olga Orozco», en Inmaculada Lergo (coord.), Territorios de fuego para una poética, Sevilla, Universidad de Sevilla.

RAMÓN, Esther (2012), «Las puertas en el muro», en Cuadernos Hispanoamericanos, págs. 745-746, 172-175. En línea. <http://www.cervantesvirtual. com/obra/puertas-en-el-muro/>. Último acceso: 30-jun-2020.

SAlazAr, Anibal (2010), «Olga Orozco y la generación neorromántica del 40. Una revisión crítica», en Inmaculada Lergo (coord.), Territorios de fuego para una poética, Sevilla, Universidad de Sevilla.

Sirimarco, María Cristina y Roque-Pitt, Héctor (1987), «Primera antología española de Olga Orozco», en Cuadernos Hispanoamericanos, 445, págs. 65-70.

Tola, Fernando y Dragonetti, Carmen (2003), «El vedismo. Los Vedas. Lo uno como origen de todo. El orden cósmico», en Boletín de la Asociación Española de Orientalistas, 39, págs.. 217-241. En línea: <http://www. cervantesvirtual.com/obra/el-vedismo-los-vedas-lo-uno-como-origende-todo-el-orden-csmico-0/>. Último acceso: 30-jun-2020.

ZonANA, Víctor Gustavo (2010), «Hacia la definición de los rasgos de estilo. El desarrollo expresivo de Olga Orozco entre 1938 y 1946», en Inmaculada Lergo (coord.), Territorios de fuego para una poética, Sevilla, Universidad de Sevilla. 


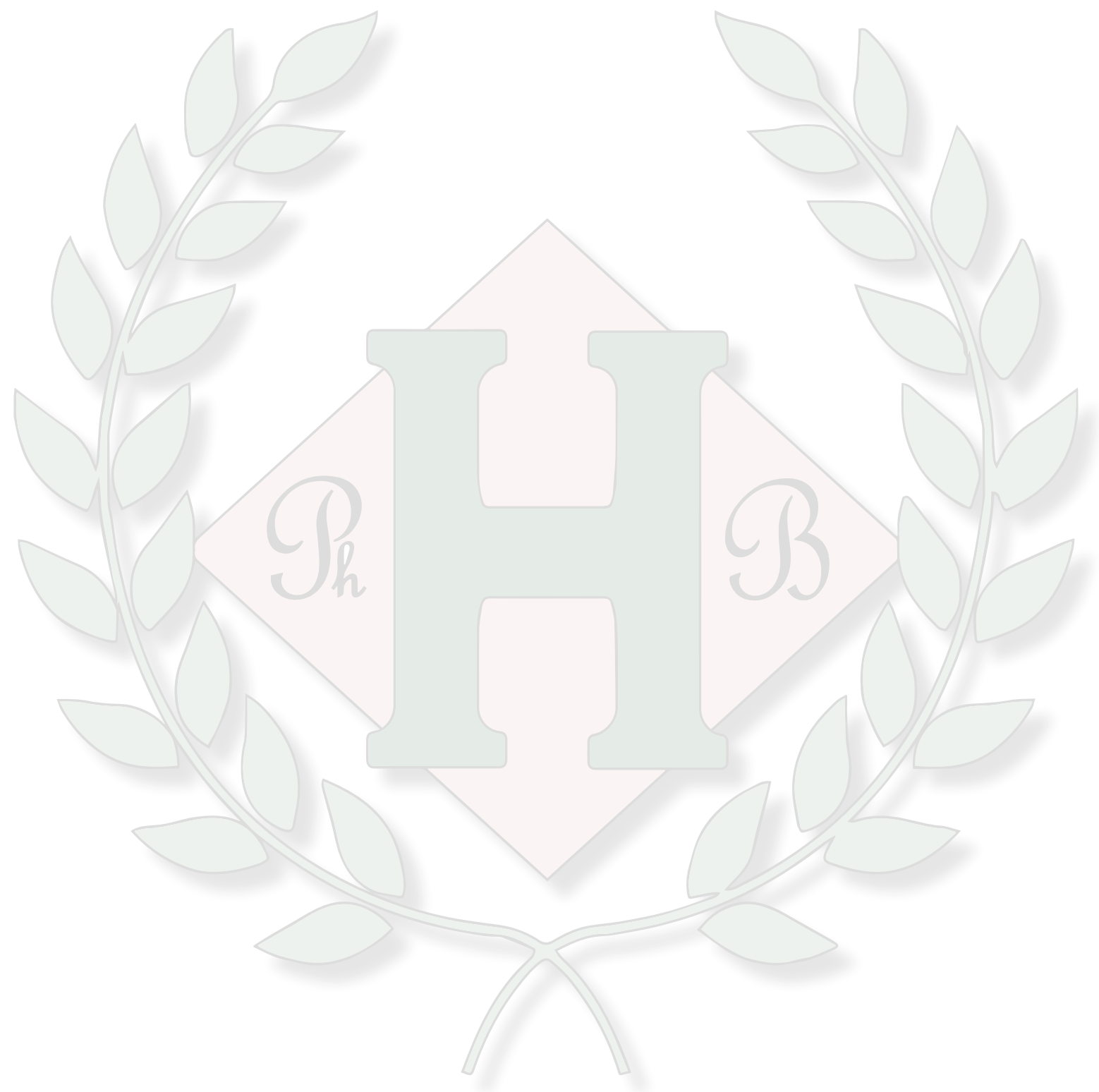

